\title{
DINAMIKA IMPLEMENTASI \\ PENYELENGGARAAN PEMERINTAHAN DAERAH
}

\author{
Oleh : \\ Achmad Namlis ${ }^{1}$ \\ Program Pascasarjana Ilmu Pemerintahan \\ Universitas Islam Riau \\ Namlis.ip@soc.uir.ac.id
}

\begin{abstract}
Abstrak
Penataan pemerintahan daerah telah melalui berbagai regulasi dan dinamika dalam implementasinya, sejak zaman kemerdekaan sampai era reformasi. Pergantian dan penyempurnaan dari satu Undang undang kepada penyempurnaannya membawa implikasi terhadap penataan kewenangan dan urusan yang dijalankan oleh pemerintahan daerah. Aksentuasinya bergulat pada apa yang harus dikerjakan pemerintah daerah dalam memberikan pelayanan dan mewujudkan kesejahteraan rakyat.Akhirnya sampai kepada UU No 23 tahun 2014 adalah penguatan kewenangan yang seimbang antara pemerintah provinsi dan Kabupaten /kota dan keterlibatan masyarakat dalam proses pembangunan.Sebelumnya menjadi kewennagan pemerintah $\mathrm{Kab} /$ kota kemudian menjadi urusan dan kewenangan pemerintah provinsi.
\end{abstract}

Kata Kunci : Implementasi dan Penataan Pemerintahan Daerah

\begin{abstract}
Abstrack
Structuring of local government has been through various regulations and dynamics in its implementation, since the era of independence until the reform era. The substitution and refinement of a law to its refinement brings implications for the arrangement of powers and affairs undertaken by local governments. Aksentuasinya grapple on what to do in the local government to provide services and realize the welfare of the people. Finally up to the Act No. 23 of 2014 is strengthening the balance of authority between the provincial and district / city government and community involvement in the development process. Previously become the government authorities kew Kabagan / the city then became the affairs and authority of the provincial government.
\end{abstract}

Keywords: Implementation and Arrangement of Local Government

\section{Latar Belakang}

Pernah dalam salah satu editorial Media Indonesia : 25 mei 2009 "Meluruskan kembali misi Otonomi Daerah " membuat kesimpulan bahwa delapan tahun pelaksanaan Otonomi Daerah justeru semakin jauh dari pencapaian.
Tidak jauh berbeda sampai sekarang mendekati dua dasawarsa otonomi itu belum nampak secara

signifikan hasilnya terhadap kemandirian daerah, sementara persoalan masih berkutat pada urusan kewenangan, pergantian dan revisi undang-undangserta persoalan anggaran dimana enampuluh tujuh persen porsinya telah 
diberikan kewenangan pengelolaannya dari pemerintah pusat ke pemerintah daerah. Tujuan akhir yang hendak dicapai oleh kebijakan desentralisasi adalah terwujudnya kemaslahatan bagi masyarakat di daerah melalui praktek demokrasi di tingkat lokal, terciptanya efisiensi dan efektifitas penyelenggaraan pemerintahan daerah, serta peningkatan pelayanan publik. (Syarif Hidayat dalam Prisma Vol.29.No 3 Juli 2010 hal,19).

Dalam sistem pemerintahan otonomi yang berlaku di Indonesia telah melalui berbagai perubahan regulasi.

Orde Baru satu-satunya pemerintahan yang memiliki kurun waktu yang paling lama dalam implementasinya melaluiUU No 5 tahun 1974, dan terus bertahan sampai masuknya era reformasi, kemudian melahirkan regulasi yang mengatur hubungan antara pusat dan daerah, dengan lahirnya UU No 22 tahun 1999 tentang PemerintahanDaerah.

Selama berlakunya UU No 5 tahun 1974 hampir-hampir tidak ada revisi , sebaliknya bila dibandingkan dengan pelaksanaan UU sebelumnya hanya mampu bertahan dalam kurun waktu yang relatif pendek yakni antara 3 sampai dengan 9 tahun. Misalnya UU pertama yang mengatur tentang pemerintahan daerah di Indonesia adalah UU No 1 tahun 1945 sebagai UU yang lahir pada fase awal kemerdekaan yang banyak mengatur tentang kedudukan Komite Nasional Daerah ( KNID) dan belum meletakkan prinsip-prinsip dasar pemerintahan itu sendiri. Dalam kurun waktu tidak lebih dari tiga tahun UU No 1 tahun 1945 terbit 23 November 1945 dalam penerapannya lebih menekankan aspek dekonsentrasi. selanjutnya digantikan UU No 22 tahun 1948

dekeluarkan tanggal 10 Juli 1948 lebih menekankan aspek desentralisasi Dalam UU ini telah memberikan pengaturan lebih eksplisit tentangprinsipprinsip dasar mekanisme penyelenggaraan pemerintahan daerah.

Selanjutnya pada tahun 1957, lebih kurang 9 tahun setelah berlakunya
UU No 22 tahun 1948, kabinet Alisastroamidjoyo mengintrodusir UU pemerintahan daerah yang baru, yaitu UU No 1 tahun 1957 tentang PokokPokok Pemerintahan Daerah yang sangat bernuansa desentralisasi ( Syarif Hidayat: 2000).

Semangat desentralisasi dalam UU No 1/1957 ini boleh dikatakan lebih lengkap dan terperinci.Kedaulatan rakyat dalam undand-undang tersebut kian diakui.Kepala Daerah semula diangkat oleh pemerintah pusat berdasarkan calon yang di ajukan Dewan Perwakilan Rakyat Daerah sekarang dipilih langsung oleh rakyat.Status Kepala daerah terpilih tidak lagi sebagai "alat pusat dan alat daerah" melainkan sepenuhnya "alat daerah"(SoetandiyoWignojosoebroto,Pri smaVol.29 2010). Namun belum sepenuhnya dapat diimplementasikan karena pemerintahan Soekarno kala itu mengeluarkan dekrit Presiden 5 juli 1959 yang mengamanatkan kembali ke UUD 1945 sementara UU No 1 tahun 1957 disusun berdasarkan UUDS 1950.

Setelah penetapan Dekrit Presiden, Soekarno mengeluarkan Penetapan Presiden (Penpres) guna mengatur penyelenggaraan pemerintahan daerah. Pertama Penpres No 6 Tahun 1959 tentang tugas dan fungsi Kepala Daerah serta Badan Pemerintahan Harian (BPH) . Kedua Penpres No 5 Tahun 1960 yang mengatur tentang tugas dan fungsi Dewan Perwakilan Rakyat Gotong Royong ( DPRD-GR) dan sekretariat Daerah.

Kedua regulasi dalam perjalanan pemerintahan selanjutnya dijadikan landasan hukum dalam mengatur relasi antara pemerintah pusat dan daerah hingga dikeluarkannya UU Pemerintahan daerah No 18 Tahun 1965, namun selang beberapa minggu nasibnya hampir sama dengan UU No 1 tahun 1957, karena Soekarno dipaksa turun dan mengakhiri kekuasaannya, MakaUU No 18 Tahun 1965 nyaris tidak dapat dilaksanakan.

Dalam masa transisi pemerintahan dari jatuhnya Orde lama ditetapkan Tap MPR Sementara ( 
MPRS) dalam pimpinan Jenderal A.Haris Nasution dengan TAP MPRS No XXI tahun 1966 yang mengamanatkan otonomi yang seluas- luasnya, bahkan azas dekonsentrasi hanya sebagai komplemen bagi azas desentralisasi. Sampai dengan tahun 1971 tidak muncul undang-undang khusus yang mengatur pemerintahan otonomi dalam pelaksanaannya. Kemudian baru pada sidang umum MPR tahun 1973 lahirlah GBHN baru sebagai hasil dari pemilihan umum tahun 1971 dengan Tap MPR No 11 tahun 1973 yang didalamnya termasuk kebijakan politis mengenai otonomi daerah yangmenganut otonomi nyata dan bertanggung jawab ( H.A.S Natabaya dkk: 2000). Selanjutnya lahirlah UU No

5 tahun 1974 yang melanjutkan nafas otonomi nyata dan bertanggung jawab sesuai dengan amanat GBHN 1973 dan menitik beratkan otonomi itu pada daerah tingkat II ( Kabupaten).

\section{Reformasi Politik Otonomi Daerah}

Reformasi di Indonesia semakin populer pasca turunnya Soeharto dari singgasana kekuasaan tahun 1998. Perkembangannya bisa dikatakan sangat drastis seperti dikatakan bahwa paradigma lama telah tumbang, seiring dengan tuntutan reformasi disegala bidang. Tuntutan reformasi yang demikian keras menyebabkan terjadinya turbulensi sistem yang akhirnya membuahkan semacam wacana yang akhirnya menjadi sebuah proses paradigma baru.

Selanjutnya menurut Winarno ( 2007) yang dikutip dari Soetandyo Wignosoebroto pertama menggunakan istilah reformasi ini adalah Paus Gregorius VII yang mencita-citakan terjadinya reformatio otius orbis ( reformasi atas seluruh tatanan dunia) dalam pustaka Inggris dikenal dengan Gregorian Reformation yang berhubungan dengan pengubahan berbagai tatanan kaidah dan tatanan nilai dalam kehidupan bermasyarakat dan bernegara.
Menurut Soetandyo reformasi Gregorian ini ditujukan untuk menggerakkan proses kearah terciptanya tatanan baru, yang salah satunya adalah pengakuan atas kekuasaan para baron dihadapan otoritas para uskup yang lantas meletakkan dasar bagi kemungkinan dipisahkannya yurisdiksi antara negara teritorial ( yang dikuasai penguasa dunia) dengan Gereja yang dikontrol oleh Paus selaku pemimpin rohani.

Penggunaan istilah reformasi kembali populer pada masa Martin Luther yang menyerukan perlunya dilakukan rekonstitusi dalam kehidupan dan ajaran kristiani. Reformasi Lutherian ini mengajarkan keharusan untuk segera melakukan proses depolitisasi gereja agar dapat berkonsentrasi pada urusanurusan yang sepenuhnya eklesiastikal, dan dengan demikian melakukan proses sekularisasi terhadap negara-negara nasional beserta hukum-hukumnya, karena geraja telah memegang peranan penting dalam menentukan alur politik kerajaan.

Dari dua pandangan diatas dapat disimpulkan bahwa reformasi adalah upaya untuk melakukan perbaikan membangun ulang atau membentuk ulang suatu struktur, dan juga melakukan perbaikan terhadap tatanan struktur yang ada. Seperti yangdilakukan Orde Baru perlu dilakukan reformasi terhadap tatanan tersebut dan diganti dengan tatanan yang lebih demokratis, tatanan yang lebih menjunjung tinggi keadilan, dan lebih menjamin hak-hak dasar manusia.

Reformasi akhirnya menjadi sebuah kesepakatan nasional untuk melakukan perubahan mendasar dalam bidang pemerintahan di daerah. Hal ini kemuian menerbitkan TAP MPR NO XV/MPR/ 1998 tentang Penyelenggaraan Otonomi Daerah ; Pengaturan dan pemanfaatan Sumberdaya Nasional yang Berkeadilan,serta Perimbangan Keuangan Pusat dan Daerah dalam Kerangka NKRI. 
Dengan TAP MPR No XV /1998 ini dapat dilihat bahwa perlunya pengaturan terhadap lebih nyata melalui otonomi daerah terutama berkaitan dengan pengaturan sumber daya nasional dan perimbangan keuangan antara pusat dan daerah. Demikian juga diberikan kewenangan yang luas dan nyata dan bertanggung jawab didaerah secara proporsional dengan pengaturan pembagian , dan pemanfaatan sumberdaya nasional antara pusat dan daerah dilaksanakan secara adil untuk kemakmuran masyarakat.

Intinya pelaksanaan otonomi daerah adalah adanya keleluasaan Pemerintahan Daerah (discreationery power) untuk menyelenggarakan pemerintahan sendiri atas dasar prakarsa, kreativitas, dan peran serta masyarakat dalam rangka mengembangkan dan memajukan daerahnya.

Menjawab tuntutan kuat terhadap otonomi sejalan dengan reformasi yang terjadi di Indonesia maka pemerintah diawal era ini mengeluarkan dua paket kebijakan tentang otonomi daerah . Pertama adalah UU No 22 Tahun 1999 tentang Pemerintahan Daerah dan UU No 25 tahun 1999 tentang Perimbangan Keuangan antara Pemerintah Pusat dan Daerah. Kedua adalah revisi dari dua UU tersebut, pertama UU No 32 Tahun 2004 tentang Pemerintahan Daerah dan UU No 33 Tahun 2004 tentang Perimbangan Keuangan antara Pemerintah Pusat dan Daerah.

Paket pertama lahir pada masa pemerintahan Presiden Habibie. UU tersebut dinilai sebagai antitesis dan kontrakonsep atas UU No 5 Tahun 1974 tentang Pokok-Pokok Pemerintahan di Daerah, produk orde Baru yang sangat sentralistis. Dengan UU No 22 Tahun 1999 membuka lebar-lebar pintu desentralisasi yang selama ini tertutup rapat. Dan dalam perjalanannya dievaluasi yang melahirkan UU No 32 Tahun 2004 dan UU No 33 Tahun 2004 pada masa pemerintahan Megawati Soekarnoputri ( Jazuli Juwaini : 2007).

Pegeseran paradigma terjadi dalam pemerintahan daerah dari structure efficiency model yang menekankan efisiensi dan keseragaman pemerintahan daerah kepada local democracy model yang menekankan demokrasi dan keberagaman dalam penyelenggaraan pemerintahan daerah. Dengan pergeseran model ini juga terjadi pengutamaan desentralisasi daripada dokonsentrasi.

Dengan dilaksanakannya UU No 22 Tahun 1999 tentang Pemerintahan Daerah diawal reformasi berakibat pada pemangkasan dan pelangsingan struktur organisasi dalam rangka menggeser organisasi pemerintahan yang seblumnya terlihat sangat gemuk ke model organisasi yang datar dan langsing. Hubungan antara Dati II dengan Dati I yang semula dependent dan subordinat bergeser menjadi independent dan coordinate. UU No 22 Tahun 1999 tidak mengenal otonomi bertingkat, bahkan tidak lagi mengenal Dati I dan Dati II, juga tidak ada hirarki antara provinsi dan Kabupaten/kota.

Pola hubungan tersebut tercipta sebagai konsekwensi perubahan dari dianutnya integrated prefectoral system yang utuh ke integrated prefectoral system yang parsial. Dianutnya integrated prefectoral system pada provinsi dengan peran ganda Gubernur sebagai Kepala Daerah (KDH) dan wakil Pemerintah dimaksudkan untuk mengintegrasikan kembali daerah otonom yang secara desentral memiliki karakteristik keterpisahan. Sementara itu kabupaten /kota telah terbebas dari intervensi pusat yang sangat kuat melalui perangkapan kepala daerah otonom(lokal self-government) dan kepala wilayah administeratif (field administerative). Dalam UU No 22 Tahun 1999 bupati dan walikota adalah kepala daerah otonom saja.

Saduwasistiono dalam sebuah diskusi bagi eselon II dan III Kab.Tegal menyebutnya paradigma, bahwa setiap UU yang mengatur tentang pemerintahan daerah di Indonesiamasingmasing menggunakan paradigma. UU No 5 tahun 1974 menggunakan paradigma penyerahan 
urusan pemerintahan. Pada UU No 22 Tahun 1999 menggunakan paradigma pengakuan kewenangan. Sedangkan pada UU No 32 Tahun 2004 digunakan pembagian urusan pemerintahan. Perbedaan paradigma tersebut berpengaruh pada kepada wewenang, kewajiban dan tanggung jawab Kepala Daerah sebagai pimpinan pemerintahan dan personifikasi daerah (Sadu Wasistiono, makalah diskusi bagi Eselon II dan III Perangkat daerah Kabupaten Tegal : 2006).

Dalam implementasinya sesuai dengan masa berlakunya ternyata melahirkan berbagai dinamika pemerintahan. Fenomena yang jelas bahwa terjadinya pergeseran pendulum kekuasaan antara "eksekutif heavy", “ kepada "legislatif heavy " DPRD begitu dominan. Dimana pada awal dimulainya otonomi daerah pada implementasinya peran legislatif begitu kuat, yang berimplikasi pada pemerintahanterutama di daerah.

Akibat perubahan yang drastis dengan kewenangan yang diberikan, tidak diimbangi dengan kerangka hukum yang stabil, mengakibatkan ekspresi cultural shock. Kasus deviasi kewenangan bermunculan didaerah. Laporan Pertanggungjawaban Kepala daerah dijadikan negosiasi politik oleh DPRD. Dan kepala daerah menjadi rajaraja kecil.

Dalam kontek yang lebih luas melihat fenomena pemerintahan dengan UU No 22 Tahun 1999 ini mendasarkan diri pada asas keragaman dalam bingkai persatuan dan kewenangan eksekutif di kurangi dibawah kekuasaan DPRD yang memaksa kepala daerah mengalihkan pertanggungjawaban kerjanya dari yang pertikal ke pusat menjadi horizontal ke dewan.Ketegangan dan konflik sering terjadi, bahkan sampai pemberhentian kepala daerah oleh DPRD karena pertanggungjawabnnya di tolak untuk kedua kalinya. Chek and balancis yang seharusnya terjadi disalah fahamisebagai politik balas dendam dan kebencian.
Disamping itu UU No 22 Tahun 1999 lemah dalam memberikan ruang partisipasi publik dalam mengontrol kebijakan. Dengan kewenangan pemerintahan daerah yang demikian besar dan dianggap utuh dan sepenuhnya dari daerah otonom. Demikian juga prilaku elit lokal dan pengingkari segala bentuk kendali dan kontrol pemerintah yang diatur dalam kerangka hukum. Hal inilah yang menimbulkan kecenderungan gerakan sentrifugal dan mendorong tumbuhnya etnosentrisme di kepolitikan elit setempat.

Kelemahan implementasi dan kurangnya regulasi yang mengakibatkan desentralisasi kehilangan arah serta kecenderungan negatif UU No 22 tahun 1999 dan UU No 25 Tahun 1999, mendorng pemerintah untuk mervisi UU tersebut, maka lahirlah UU No 32 Tahun 2004 tentang Pemerintahan Daerah dan UU No 33 Tahun 2004 tentang Perimbangan Keuangan antara Pemerintah Pusat dan Daerah.

\section{Prinsip Otonomi dalam UU Pemerintahan Daerah}

Berdasarkan kelemahan dalam implementasi UU No 22 Tahun 1999 yang dilaksanakan pada masa transisi pemerintahan, karena begitu reaksioner atas kondisi sosial politik masa itu, akibatnya kurang mampu memberikan kerangka hukum yang stabil, maka lahirlah revisinya dengan UU No 32 Tahun 2004 yang terdiri dari $16 \mathrm{Bab}$ dan 240 pasal.

Penerapan UU No 32 Tahun2004 ini tetap menggariskan bahwa otonomi tetap dengan prinsip otonomi luas, nyata dan bertangung jawab. Dalam penjelasannya disebutkan bahwa yang dimaksud dengan otonomi luas adalah daerah diberikan kewenangan mengurus dan mengatur semua urusanpemerintahan diluar yang menjadi urusan pemerintah yang ditetapkan dalam UU ini. Daerah memiliki kewenangan membuat kebijakan daerah untuk memberi pelayanan, peningkatan peran serta, prakarsa, dan pemberdayaan 
masyarakat yang bertujuan pada peningkatan kesejahteraan rakyat.

Sementara yang dimaksud prinsip otonomi nyata adalah bahwauntuk menangani urusan pemerintahan dilaksanakan berdasrkan tugas, wewenang, dan kewajiban yang senyatanya telah ada dan berpotensiuntuk tumbuh, hidup, dan berkembang sesuai dengan potensi dan kekhasan daerah. Dengan demikian isi dan jenis otonomi bagi setiap daerah tidak selalu sama dengan daerah lainnya. Adapun yang dimaksud otonomi bertanggung jawab adalah otonomi dalam penyelenggaraannya harus benar-benar sejalan dengan tujuan dan maksud pemberian otonomi, yang pada dasarnya memberdayakan daerah termasuk meningkatkan kesejahteraan rakyat yang merupakan bagian utama dari tujuan nasional.

Maka dalam UU No 32 Tahun 2004 memberikan definisi asas-asas penyelenggaraan pemerintahan daerah sebagai berikut: Desentralisasi adalah penyerahan wewenang pemerintahan oleh pemerintah kepada daerah otonom untuk mengatur dan mengurus urtusan pemerintahan dalam sistem Negara Kesatuan Republik Indonesia. Dekonsentrasi adalah pelimpahan wewenang pemerintahan olehpemerintah kepada Gubernur sebagai wakil pemerintah dan/atau kepada instansi vertikal di wilayah tertentu. Tugas pembantuan adalah penugasan dari pemerintah kepada daerah dan/atau desa serta dari pemerintah kabupaten

/kota kepada desa untuk melaksanakan tugas tertentu.

Maka ditilik dari perbandingan kewenangan urusan yang diberikan kepada daerah sejak UU No 5 Tahun 19974, UU No 22 Tahun 1999, dan UU No 32 Tahun 2004 pergeseran pendulumnya dari sentralistik kepada desentralistik, kemudian berkeseimbangan ( Sadu Wasistiono Makalah diskusi Kab.Tegal 2006).

UU No 32 Tahun 2004 ini juga dengan sendirinya menghapuskan dekonsentrasi pada tingkat kabupaten/kota sebagaimana dalam pelaksanaan UU sebelumnya, dan semua kewenangan dalam rangka desentralisasi diberikan kepada daerah untuk mendekatkan pelayanan kepada masayarakat.

Namun dalam perjalanannya ternyata UU No 32 Tahun 2004 ini masih banyak ditemukan kelemahan dan kekurangan sesuai dengan dinamika ketatanegaraan dan pemerintahan. Hal ini berkaitan dengan konsep negara kesatuan, pembagian kewenangan antara pemerintah pusat dan daerah, penyelenggaraan pemerintahan daerah, pemilihan kepala daerah langsung, perimbangan keuangan, pemerintahan desa, pengawasan dan pembinaan pelaksanaan otonomi daerah.

Berbagai dinamika dalam perubahan kebijakan pemerintahandaerah sebagai negara kesatuan tentu menerapkan pembagian urusan pusat dan daerah, dan tetap mengacu pada pola desentralisasi.Dan pada dasarnya mengacu pada " ultra vires doctrine" dan " residual power" atau " open and arrangement" ( konsep kekuasaan asli atau kekuasaan sisa). Kekuasaan sentralistik memang lebih terasa pada ultra vires doctrine karena kewenangan yang diberikan kepada daerah dirinci satu persatu.Dan residual power lebih mengarah kepada desentralisasi.

UU No 32 tahun 2004 dan diganti dengan UU No 23 tahun 2014 kewenangan yang diberikan kepada daerah lebih bersifat "Residual Power" atau "open and arrangement" karena semua kewenangan diberikan kepada daerah kecuali urusan yang ditangani oleh pemerintah pusat, yakni moneter dan fiskal nasional, pertahanan dan keamanan, urusan luar negeri, peradilan dan agama. Maka UU No 23 tahun 2014 tentang Pemerintahan daerah menjadi 27 Bab dan 411 pasal. Disamping perubahan yuridis maka terjadi juga perubahan filosofis berkaitan dengan makna dan orientasi secara tersurat terkandung dalam pasal-pasal yang sebelumnya tidak diatur dalam UU No 32 tahun 2004. 
Disamping itu pendekatan penguatan provinsi begitu jauh, dengan cara menarik urusan yang selama ini dikelola oleh kabupaten/kota (pertambangan, kehutanan, kelautan dan perikanan) menariknya keatas menjadi urusan provinsi. Urusan pemerintahan dibagai atas urusan mutlak yang diselenggarakan oleh pemerintah pusat , urusan pemerintah kongkuren yang dibagi antara pemerintah pusat, pemerintah Daerah Provinsi dan Pemerintah Daerah Kab/Kota. Disamping itu yang tidak diatur dalam UU No 32 tahun 2004 , kini dipertegas dalam UU No 23 tahun 2014 misalnya tentang informasi pemerintahan daerah.

Pemerintahan daerah wajib menyediakan informasi pemerintahan daerah yang terdiri atas: a.Informasi pembangunan daerah $b$. Informasi keuangan daerah yang dikelola dalam satu sistem informasi pemerintahan daerah ( Pasal 391 ayat 1 dan ayat 2). Sejalan dengan itu adalah penguatan partisipasi masyarakat untuk ikut aktif dalam proses pembangunan dengan tujuan membangun keterbukaan kepada masyarakat di daerah.

\section{Daftar Kepustakaan}

di Keamatan, M. P. N. S., \& Hulu, S. Evaluasi Pelaksanaan Peraturan Pemerintah Nomor 45 Tahun 2007 Tentang Persyaratan dan Tata Cara Pengangkatan Sekretaris Desa.

Ispik, A., Yogia, M. A., Wedayanti, M. D., \& Zainal, Z. (2021). The Influence of Discipline on Performance of Employees Office of the Ministry of Religion. Pekanbaru City.

Subhayano, T., Yogia, M. A., Wedayanti, A. A. P. M. D., \& Zainal, M. L. H. (2021). Good Governance in Maintaining Peace and Order at Pangkalan Kerinci

District. Pelalawan Regency.

Ispik, A., Yogia, M. A., Purwati, A. A., Wedayanti, M. D., \& Zainal, M. L. H. (2021). Analysis of Benefits, Discipline and Leadership Style in improving Employee Performance of the Ministry of Religion in Pekanbaru, Indonesia.

Nasri, H., Nurman, N., Azwirman, A., Zainal, Z., \& Riauan, I. (2022). Implementation of collaboration planning and budget performance information for special allocation fund in budget planning in the regional development planning agency of Rokan Hilir regency. International Journal of Health Sciences (IJHS) Ecuador, 6(S4), 639-651.

Munir, A., Wahyudi, S., \& Zainal, Z. (2020). Tinjauan Kriminologi Terhadap Sensual Marketing Sebagai Strategi Pemasaran Produk Yang Diperankan Oleh Sales Promotion Girl Di Kota Pekanbaru. Wedana: Jurnal Kajian Pemerintahan, Politik dan Birokrasi, 6(2), 21-35.

Subhayano, T., Yogia, M. A., Wedayanti, M. D., \& Zainal, Z. (2021). The Role of the Camat in Coordinating the Administration of Peace and Order in Pangkalan Kerinci District Pelalawan Regency.

Suwaryo, H. U., \& Redjo, H. S. I. (2018). Transformasi Hubungan Pemerintah Pusat Dan Pemerintah Daerah Dalam Pemberian Izin Hutan Tanaman Industri Bagi Swasta Di Provinsi Riau Tahun 2010-2015.

Wicaksono, A. (2022, April). Peatlands Restoration Policies in Indonesia: Success or Failure? In IOP Conference Series: Earth and Environmental Science (Vol. 995, No. 1, p. 012068). IOP Publishing.

Yogia, A. S. M. A., Rahman, Z. M. D. W. K., \& Purwati, A. A. (2021). Leadership of Tourism and Culture Department in Development of Cultural Reserves at District Kuantan Singingi.

Zainal, Z., Rambey, R. R., \& Rahman, 
K. (2021). Governance of Household Waste Management in Pekanbaru City. MIMBAR: Jurnal Sosial dan Pembangunan, 37(2).

Zainal, Z., \& Nurdasanah Putri, F. (2021). Government Management in VillageOwned Enterprises in Increasing Village Original Income In Kampar District.

Zainal, Z. (2016). Dinamika Kebijakan Pemerintahan Desa Di Indonesia Dari Masa Ke Masa (Studi Tahun 19792015). Jurnal Tapis: Jurnal Teropong Aspirasi Politik Islam, 12(1), 19-36.

Halim, N. A., Rosidi, I., Haris, A., Yesicha, C., \& Riauan, M. A. I. Media dan Politik.

Riauan, M. A. I., Aziz, A., \& Nurman, N. (2020). Analisis Framing" Aksi Bela Islam" sebagai Dakwah Islam di Riau Pos (A Framing Analysis of" Islam Defense Action" as Islamic Dakwah on Riau Pos Newspaper). Jurnal Dakwah Risalah, 31(1), 35-47.

Riauan, M. A. I., Qurniawati, E. F., Aslinda, C., \& Aziz, A. (2020). Konstruksi Realitas Pada Pesan Politik Calon Walikota Pekanbaru di Riau Pos. ETTISAL: Journal of Communication, 5(1).

Riauan, M. A. I., Kholil, S., \& Sikumbang, A. T. (2019). Islamic Symbols on Political Messages in Newspapers in Riau (Study in Regional Head Election 2017). Budapest International Research and Critics Institute-Journal

(BIRCIJournal), 2(1), 254-262.

Riauan, M. A., Sari, G. G., Aslinda, C., \& Qurniawati, E. F. (2018). Konstruksi Makna Ketergantungan dalam Perilaku Merokok. Relasi Negara Industri Dan Masyarakat Dalam Perspektif Komunikasi, 171.

Riauan, M. A. I., \& Shasrini, T. (2017). Dampak Komunikasi Terapeutik terhadap Citra Pelayanan Kesehatan (Studi Kasus di Rumah Sakit Umum Daerah Arifin Achmad
Pekanbaru). Jurnal

Messenger, 9(1), 31-43.

Riauan, M. A. I. (2016). Figur Politik Calon Walikota Pekanbaru Septina Primawati Rusli dan Erizal Muluk Pada Pemilukada Kota Pekanbaru 2011. Medium, 4(2).

Riauan, M. A. I. (2013). Penggunaan Teknologi Komunikasi dalam Penerapan Good Governance. Jurnal Kajian Pemerintahan, 2(2), 102-107.

Riauan, M. A. I. (2012). Studi Komparatif Aktivitas Humas Antara Pemerintah Provinsi Riau dengan PT. Chevron Pacific Iindonesia. Medium, 1(1).

Sari, G. G., Wirman, W., \& Riauan, M. A. (2018). Pergeseran Makna Tradisi Bakar Tongkang Bagi Generasi Muda Tionghua di Kabupaten Rokan Hilir Provinsi Riau. 